\title{
PERCORRENDO AS MARCAS DE DISTINTAS TEMPORALIDADES NO BAIRRO BOMFIM: Exercício de etnografia nas ruas de um bairro.
}

Vanessa Zamboni

Ana Luiza Carvalho da Rocha e Cornelia Eckert Orientação)

\section{Introdução}

A Antropologia urbana, realizada no âmbito das pesquisas com sociedades urbano-industriais, tem por objetivo compreender de que modo os fenômenos sociais são produzidos, reproduzidos e vivenciados na vida cotidiana do homem comum.

Esta área de conhecimento em seus primórdios preocupou-se em estudar e conviver com "povos exóticos" aos antropólogos e a sua própria cultura. No decorrer de seus trabalhos de campo os antropólogos enfrentaram diversas dificuldades e aprenderam a transformar estas dificuldades iniciais em condição e instrumento de pesquisa (MAGNANI, 1984).

Em sociedades em que os padrões culturais se encontram muito diferentes dos seus é necessário que o antropólogo esteja atento a diferentes gestos, palavras, hábitos, etc, por mais que pareçam banais e insignificantes. E é nesse ponto que reside à máxima antropológica "estranhar o familiar.” (DaMatta, 1974)

Para um antropólogo que estuda em sua própria sociedade um dos maiores desafios é a familiaridade, podendo se transformar em obstáculo, pois ela pode representar idéias pré-concebidas, ou acaba por simplesmente banalizar aspectos importantes do cotidiano dos grupos estudados.

Nesse sentido, a escolha pelo universo de pesquisa que é um bairro de Porto Alegre, o BomFim, no qual também sou moradora representa um duplo desafio.

Iniciando pelo meu processo de formação de iniciação científica em antropologia, no qual além das disciplinas cursadas na faculdade de Ciências Sociais, o trabalho de campo é uma experiência de iniciação à pesquisa antropológica. Ao observar diretamente no universo de pesquisa, a prática toma um outro tom, na qual juntamente com orientações e leituras de textos sobre o tema pesquisado, passamos a viver na prática dilemas e conflitos de realizar nossas investigações no meio urbano. Relacionando a experiência de 
estar junto com o outro, observando fenômenos e buscando uma reflexão associada a teorias e métodos e técnicas da própria disciplina aprendendo nos desafios dialogando com antropólogos que realizaram seus trabalhos e podem contribuir com suas experiências e teorias criadas a partir delas.

Assim, o desafio é transformar conceitualmente essa experiência seguindo algumas metodologias, técnicas e um aporte conceitual que dê conta dos fenômenos experenciados na vida urbana dos grupos estudados no meio citadino, implicando em um deslocamento epistemológico por parte do pesquisador. Nesse ponto, o estranhamento do familiar, é um processo no qual o investigador que desenvolve pesquisa no meio urbano se depara já que é necessário ir além do superficial, adentrando nos fenômenos, fazendo reflexões, dialogando com as teorias que possam dar conta dos fenômenos encontrados em campo.

Nesse sentido, durante o desenvolvimento do exercício etnográfico, deparavame com questões sobre o fazer etnográfico no meu próprio bairro, me despindo de alguns préconceitos e redescobrindo-o com um aporte conceitual e uma metodologia que permitisse que trazer algum conhecimento antropológico sobre questões relacionadas as formas de vida urbana na cidade de Porto Alegre. O processo de relativização foi buscado, de diferentes formas, sendo que era, inicialmente, a principal dificuldade: me despir de visões de apenas uma moradora, e fazer com que esse meu papel não influenciasse um olhar pré-concebido sobre o lugar.

Para atingir a meta de estudar o meu próprio bairro se fez necessário utilizar determinados métodos de registro dos dados de campo, e passar por um processo de desconstrução das formas habituais com as quais interajo com meus vizinhos, os moradores locais, e de aprofundamento das representações sociais que eles possuem, e eu mesma, a respeito da vida cotidiana no bairro. Durante o campo, o fato de ser moradora do bairro e freqüentadora habitual de seus espaços de sociabilidade me impôs determinadas dificuldades em campo. A primeira é ter que me despir deste papel social no interior do bairro BomFim à medida que iniciava meu processo de observação participante nos território eleito para esta pesquisa: a rua. Neste processo tratava-se de suspender minhas categorias de pensamento viciadas, por um olhar de classe, muitas delas pertencendo de certa forma a visões de senso comum, para partir para uma "descrição densa" (GEERTZ, 1978) dos acontecimentos vividos em campo.

O método utilizado foi, portanto, o etnográfico realizado através da técnica da observação direta e participante em vários territórios do bairro Bom fim e através da técnica 
da "etnografia de rua" (ECKERT e ROCHA, 2003) onde o pesquisador realiza caminhadas no local, observando o espaço e suas configurações, interagindo com atores que participam da vida social. A máquina fotográfica, na etnografia de rua, também é um instrumento que auxilia nessas interações no espaço público da rua, além desse instrumento possibilitar um outro olhar sobre a configuração social no espaço urbano atentando para diversas situações, não sendo apenas um registro destas, mas um recorte, na busca de imagens que possam falar sobre a existência social dos diferentes grupos urbanos.

Ambas as técnicas foram acompanhadas da realização de entrevistas não estruturadas com moradores locais e usuários de estabelecimentos comerciais, de lazer e recreação, com o objetivo de conhecer os valores, as formas de pensar e agir dos distintos grupos urbanos que se apropriam de diferentes territórios do bairro e compreender as suas práticas diversas de lazer e consumo.

O primeiro passo foi fazer um (re)conhecimento do bairro, utilizando as técnicas de etnografia de rua (ECKERT e ROCHA, 2003) e de " caminhadas pelo bairro" (DE CERTAU, 1998), onde o pesquisador é desafiado a realizar uma espécie de mapeamento e cartografia de um território, observando-o de acordo com a totalidade de seus trajetos e percursos, para a partir disto analisar os diferentes fluxos de pessoas e apropriações dos seus lugares.

Durante o transcorrer do trabalho de campo realizado por mim o Bairro BomFim fui levantando muitas dúvidas e questões sobre o fazer antropológico numa grande metrópole: as dificuldades de estar em campo, o desconforto de pesquisar meu próprio grupo social, as necessidades de escrever como forma de obter o distanciamento do processo de realização de minhas observações participantes, o prazer de se dar conta de determinados fenômenos da vida coletiva no bairro até então invisíveis para mim num primeiro olhar, a riqueza de ouvir o relato da vida das pessoas com quem compartilhava meu trabalho de campo, etc.

Refletir sobre o grau de implicação da subjetividade do pesquisador está presente no exercício antropológico. O desafio de pensar o desempenho de outro papel junto à vida dos moradores locais, e que me permitiu legitimar junto a eles a minha experiência de pesquisa com a realidade do bairro que, em outra circunstância de minha vida neste território, não teria sido possível, incluo aí o caso dos moradores de rua que foram, posteriormente, por mim entrevistados.

Nesta empreitada de buscar uma boa condição de trabalho de campo, onde minha subjetividade possa ser por mim interpretada na busca de uma maior compreensão da 
vida cotidiana dos moradores do bairro BomFim, seus habitues, a máquina fotográfica foi importante instrumento, já que, por diversas vezes me permitia uma maior aproximação com as pessoas, seja na rua, seja em locais de consumo, estabelecimentos comerciais, através dos quais pude finalmente registrar pequenos instantes do bairro em transformação.

O olhar pela máquina fotográfica também influencia na possibilidade de construção do próprio olhar etnográfico, já que o que vai ser fotografado é também direcionado a partir de aportes conceituais e do recorte da pesquisa. O que se fotografa em campo está pautado no que é uma foto etnográfica. Trabalhando com a perspectiva da fotografia como representação do real e não uma cópia fidedigna a máquina fotográfica como instrumento de pesquisa também acaba causando um estranhamento que provoca naquele que a usa como forma de registro das práticas culturais e sociais.

Da mesma forma, a pesquisa com as imagens de acervo deste território na base de dados do BIEV (Banco de Imagens e Efeitos Visuais), junto com a etnografia visual atual do bairro, tanto quanto a leitura de textos escritos por cronistas e romancistas sobre esta área da cidade de Porto Alegre e as entrevistas não-diretivas realizadas junto aos moradores e habitues do local que encontrava ao longo de minhas caminhas pelas ruas e avenidas do BomFim, foram, todas elas, importante para atingir a relativização de minha experiência ordinária no local a medida que compreendia as transformações da paisagem do bairro nas diferentes épocas .

O objetivo deste artigo é, portanto descrever alguns dos estilos de vida dos grupos que se apropriam do bairro BomFim, moradores ou não, segundo as visões de mundo e trajetórias de diferentes destes indivíduos e/ou grupos num território da vida urbana portoalegrense marcado pela pluralidade de universos simbólicos. Alguns trabalhos sobre esta temática já foram realizados no próprio bairro BomFim, como o artigo de Ana Luiza Carvalho da Rocha (2001), onde a autora nos traz os diferentes estilos de vida encontrados no bairro, a partir de uma visão de um grupo de crianças moradoras do bairro e de como estas se apropriam dos espaços na vida cotidiana dessa área da cidade. Trazendo diversas imagens e identidades associadas a esse território da cidade, envolvidas nas tramas da vida urbana.

A dissertação Nem tudo que reluz é ouro, de Elena Salvatori (2000) também abordou formas de vida social em um bairro de prestígio em Porto Alegre, o bairro Bela Vista, trazendo as trajetórias de vida dos moradores, seu estilo de vida e visões de mundo inseridas em seu universo simbólico. Trata de um espaço socialmente construído, associado a representações de um estilo de vida de classe alta na cidade de Porto Alegre. 
O bairro Bom fim na cidade está associado e por diversas vezes representado como um bairro de classe média, composto por uma pluralidade de territórios (ROCHA, 2001).

O interesse em compreender as práticas sociais dos moradores do BomFim em relação a este espaço da cidade partiu de observação e questionamentos acerca dos diferentes espaços e universos simbólicos existentes no interior da vida social do bairro, explicitada na configuração espacial, em diferentes locais e em diferentes horas do dia, ou na noite, assumiam um significado distinto com diferentes apropriações pelas pessoas.

O fato de eu ser moradora do Bairro há 3 anos, vinda do interior para cursar a graduação em Ciências Sociais modificava minha relação com o bairro. A experiência de como bolsista de Iniciação científica no BIEV (Banco de Imagens e Efeitos Visuais), núcleo que trabalha também com Antropologia Visual e Antropologia Urbana sob Coordenação de Cornelia Eckert e Ana Luiza Carvalho da Rocha, permitiu com que eu tivesse contato com a etnografia fazendo através de exercícios etnográficos na cidade de Porto Alegre. Onde cada bolsista de iniciação científica, realiza pesquisa individual, de acordo com o projeto maior do núcleo, produzindo imagens e entrevistas que além de aprender a "fazer antropológico" alimentam o Banco de Imagens e Efeitos Visuais (BIEV).

O meu primeiro exercício etnográfico no BIEV orientado por Ana Luiza Carvalho da Rocha foi realizado na área central de Porto Alegre, num estudo sobre memória coletiva das antigas profissões urbana com um grupo de floristas e fotógrafos lambe-lambe que trabalham nesta parte da cidade. Tratava-se de remontar as transformações urbanas que ocorrem no centro de Porto Alegre partir de práticas e saberes tradicionais de trabalhadores urbanos que ali encontram seu sustento.

Estudando este processo de transformação da paisagem urbana, o meu interesse pela paisagem do BomFim cresceu quando acompanhei em campo uma colega de pesquisa junto ao BIEV, por ocasião da demolição do Cine Baltimore. A demolição deste antigo cinema - símbolo do bairro - ao mesmo tempo em que ocorria o fechamento do Bar do João devido a obra ter atingido a estrutura do prédio - estava sendo bastante discutido entre os moradores do local.

A demolição do Cine Baltimore e do fechamento do Bar João, modificava toda a lógica de uso habitual do espaço da calçada no trecho da Av. Osvaldo Aranha, entre a Rua João Teles e Felipe de Oliveira, por determinados grupos de jovens que costumavam ficar até altas horas em frente ao bar e ao cinema. As lembranças da antiga troca social no interior do Bar João e das suas famosas cachaças contrapunham-se a multidão de jovens reunidos na 
calçada deste trajeto da Av. Osvaldo Aranha, deixando alguns de seus moradores, os mais antigos, descontentes com as transformações sofridas pelo bairro nas últimas décadas, sendo que para alguns tratava de se identificar com um novo projeto para o bairro que viria com a demolição do Baltimore.

A destruição do Cine Baltimore significou a criação de um espaço nobre a ser preenchido pela especulação imobiliária no local, estando prevista a construção de um centro comercial na área que antes era ocupado pelo cinema, o que vem gerando uma polêmica entre os moradores do bairro BomFim quanto aos novos usos desta área.

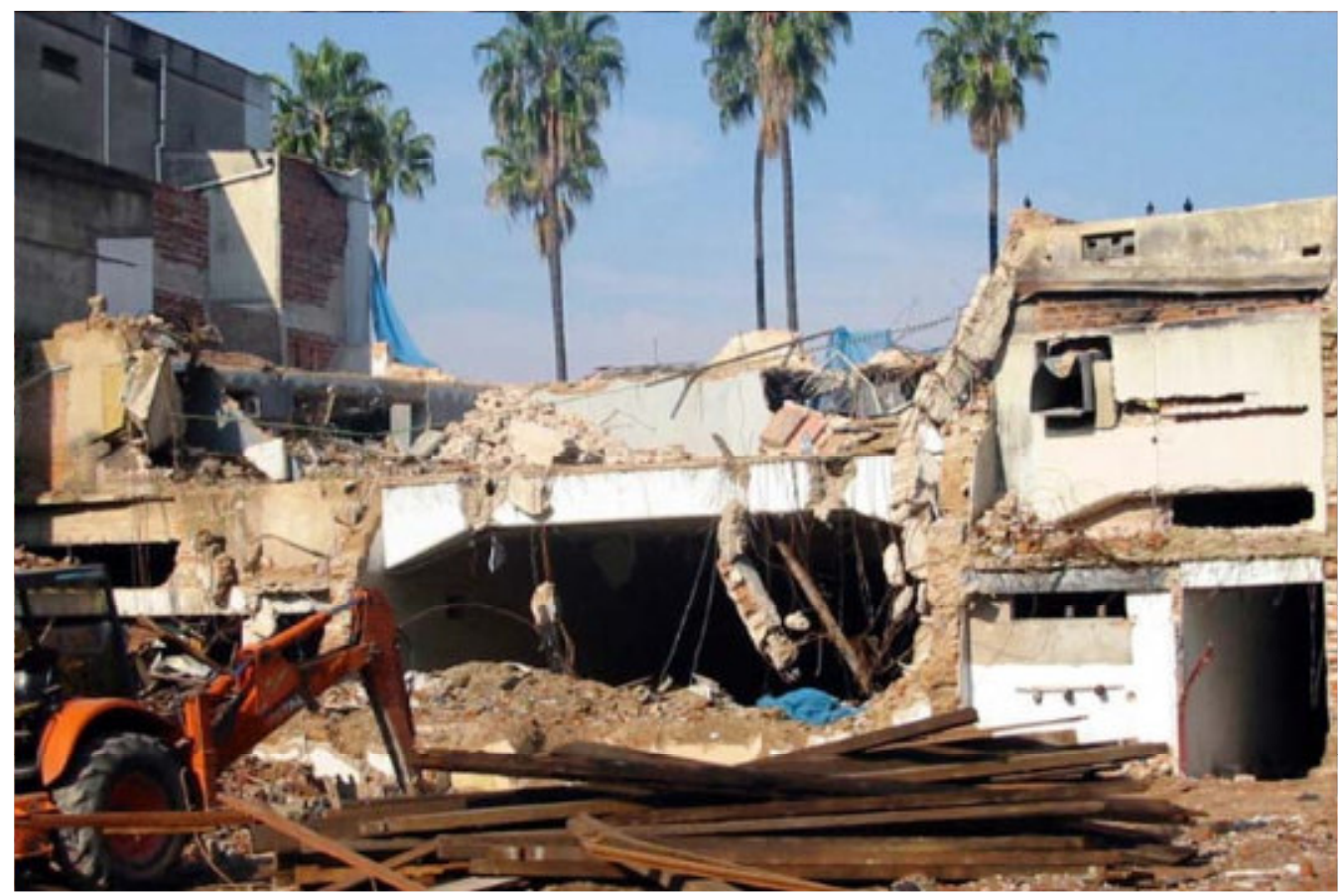

A demarcação das formas de sociabilidade em conflitos em certas regiões do bairro BomFim fazem dele um espaço onde podemos verificar diversos territórios alvos de disputas e conflitos por distintos grupos. Nesse sentido, acompanhando o jornal da Associação dos moradores dos últimos dois anos, por diversas vezes a capa e o tema central das reportagens é o espaço do bairro. A utilização e apropriação do espaço que às vezes esta ligada a presença do tráfico na Avenida Principal, a Osvaldo Aranha, a violência, a jovens e bares que servem de palco para sociabilidades pautadas na boêmia, consumo de bebida alcoólica, drogas, música. O tema da violência no BomFim é visto nos jornais e da mídia televisiva local, sobre os enfrentamentos entre a polícia e a população de jovens, as batidas policiais na Avenida Osvaldo Aranha. Esta que tem um histórico de ocupação freqüentando á noite desde os idos dos anos 90. 

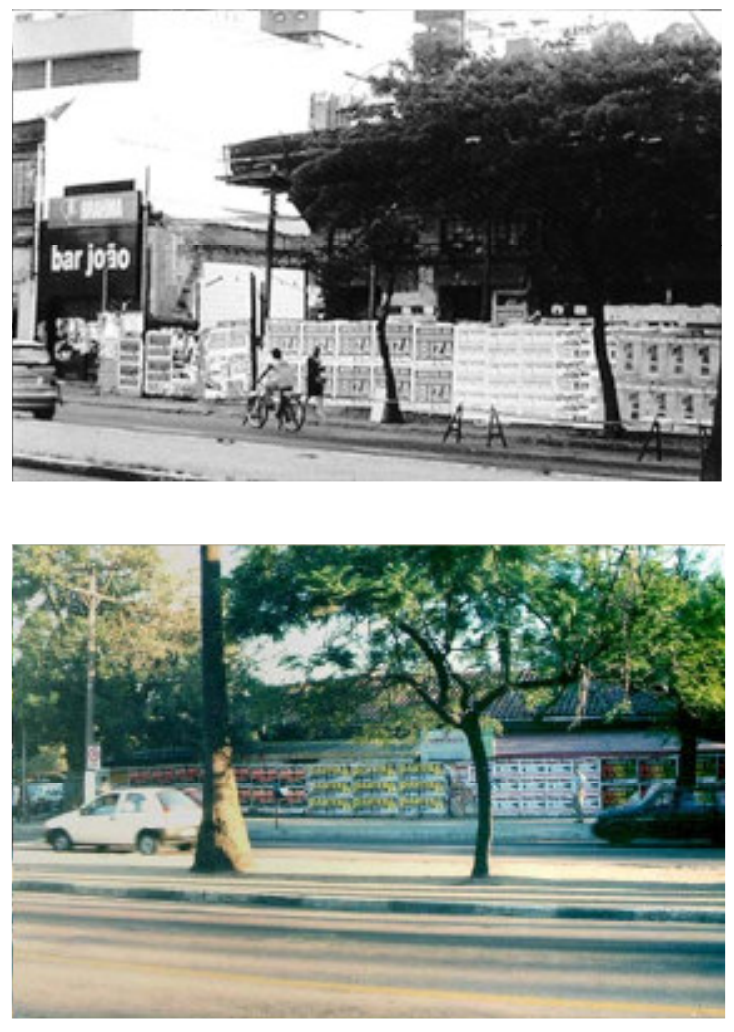

Alguns locais atualmente ainda são vistos como resquícios desse tempo, onde a sociabilidade noturna, boêmia pelo menos para um grupo da população, exemplo disso são as reportagens veiculadas pelo jornal da associação comunitária do BomFim. Onde o Scaler e outros bares emblemáticos do

Mercado Público do BomFim, são colocados enquanto locais nocivos para o bairro e a população, onde há música alta, barulho, tráfico e consumo de drogas, enfim a "desordem". Um projeto de lei previa a proibição da reprodução de qualquer tipo de música nos bares e restaurantes do Mercado público, sendo apenas possível e dentro da

lei, tocar músicas da MPB. Esse desejo manifestado pela associação dos moradores, mesmo que esta apenas comporte uma pequena parcela da população não representando a totalidade das visões dos moradores, nos traz a temática da busca pela reordenação das sociabilidades e dos espaços, trazendo a tona através das tensões e diferentes visões as distintas regiões morais encontradas no bairro.

Quanto aos espaços distintos, segundo Robert Park (1916) é inevitável que indivíduos que buscam as mesmas formas de diversão:

\footnotetext{
“(...), devem de tempos em tempos se encontrar nos mesmos lugares e a população tende a se segregar, não apenas de acordo com seus interesses, mas de acordo com seus gostos e temperamentos. Assim, cada vizinhança, sobre as influências que tendem a distribuir e segregar as populações citadinas, pode assumir o caráter de uma região moral." (PARK, 1916)
}

Fazendo uma reflexão em torno destes espaços que podem se transformar em regiões morais destaco aqui o Mercado Público do BomFim que situa-se em uma das bordas do Parque da Redenção. Atualmente, de um lado fica um parque de diversões. Enfim, dois locais que comportam sociabilidades distintas no que se refere ao lazer na cidade. De um lado a boêmia noturna, a música, a bebida, de outro crianças, doces, um espaço mais diurno. Espaços estes que configuram o espaço urbano do Bom fim como um "território plural" 
(ROCHA, 2001), mas, sem deixar de provocar tensões e conflitos, entre as distintas regiões morais, pautadas também pelos diferentes regimes do dia. Um local também polêmico, enquanto um espaço público da cidade representativo da identidade do bairro.

Planos e projetos de cercamento do parque já foram levantados e passaram por um plebiscito popular, onde o resultado foi pelo não cercamento. Essas preocupações acabam por refletir tensões e conflitos em relação aos espaços e as sociabilidades. O Parque da Redenção serve de palco para distintas apropriações pelos habitantes da cidade, sendo local de lazer e práticas esportivas durante o dia, consumo e lazer aos Sábados e Domingos no Brique, onde famílias e amigos se encontram para tomar um chimarrão e a noite como espaço de encontros e programas de homossexuais e garotos de programa.

Distintas temporalidades marcam as formas de sociabilidade no interior do bairro e desenham seus limites internos tanto quanto das fronteiras do bairro BomFim com outros bairros, em especial no que se refere às práticas de lazer e consumo e na demarcação que estas estabelecem para a própria apropriação da rua pelos diferentes grupos urbanos.

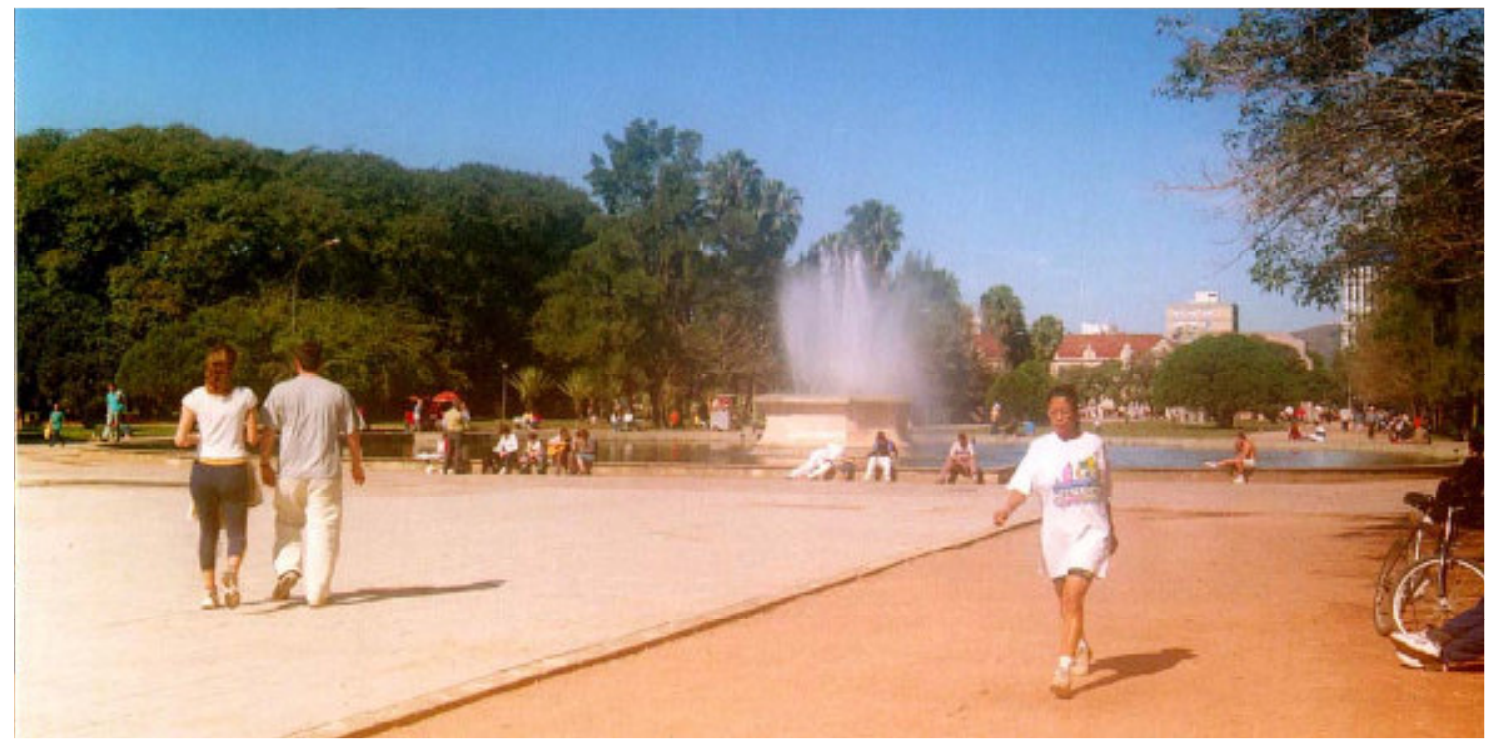

\section{Caminhadas Pelo Bairro}

O mapeamento do bairro ocorreu com base nas leituras do texto "Caminhadas pela cidade", contido na obra de M. De Certau (1998), atenta as formas de apropriação do espaço da rua pelos indivíduos e/ou grupos que por ali costumam passar e aos pequenos fatos do cotidiano que tendemos a banalizar. Tratava-se de caminhadas através das quais eu buscava sistematizar minhas idas a campo, na exploração atenta ao espaço das ruas do bairro, das suas residências - casas e prédios de apartamentos, e de suas lojas comerciais, e que me 
permitiram, inclusive, minha aproximação com as pessoas segundo os diferentes grupos urbanos ali situados.

As caminhadas pelo bairro foram dadas no sentido de subida e descida nas ruas com a intenção de penetrar no interior do bairro. Em diferentes horários do dia e dias da semana, realizei uma espécie de zig zag pelas ruas e avenidas seguindo diferentes entradas e percursos.

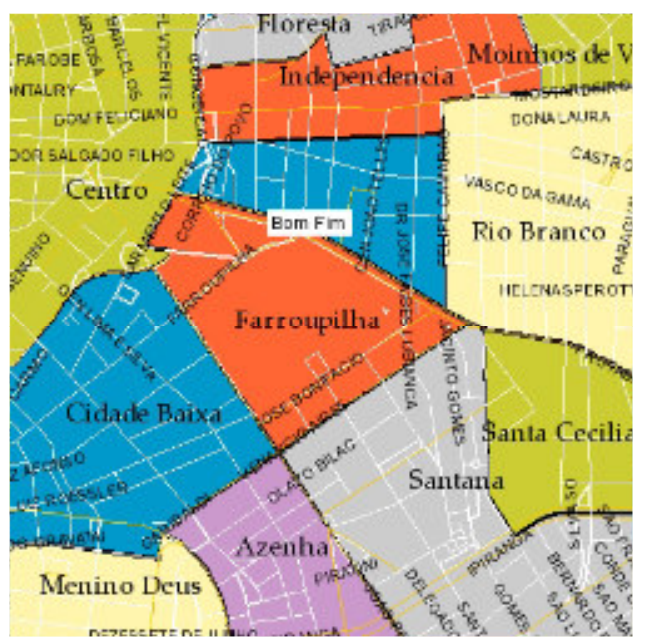

Os limites utilizados para isso, duas grandes e importantes avenidas da cidade. A Avenida Independência que se situa ao norte e a Avenida Osvaldo Aranha ao sul. Entre estas largas avenidas existe maior concentração de equipamentos urbanos, como hospitais, corredores de ônibus ligando o centro a outras regiões da cidade, bem como maior concentração de lojas e comércio. Aumentando assim, o fluxo de passantes.

Mas, embora sejam duas Avenidas das quais podemos considerar limítrofes do bairro não podem ser consideradas como um espaço esteticamente homogêneo. Pelo contrário assumem características esteticamente diferenciadas no que diz respeito a sua apropriação.

Nas roupas dos passantes, nos edifícios e na espécie de estabelecimentos e até nos preços de aluguéis e de venda de imóveis podemos verificar essa distinção.

A Avenida independência está mais próxima a bairros considerados mais "nobres" da cidade como o Moinhos de Vento, Auxiliadora, Mont'serrat. Enquanto a Avenida Osvaldo Aranha faz divisa em grande extensão com o Parque da Redenção, e bairros considerados de classe média como a Cidade baixa e o bairro Santana.

No trecho próximo a Avenida Independência subindo a Rua Ramiro Barcellos onde inicia formalmente o BomFim, chamam a atenção lojas, ou mercados, estéticas e prédios com um ambiente mais clean, ou seja, ambientes claros, limpos.

Lojas de roupas de gala e de noiva, estilistas, galerias amplas e requintadas nas suas fachadas e nos seus nomes prédios altos e grandes e novos. Encontramos também muitas árvores nas calçadas, com troncos grandes, onde na primavera muitas flores delicadas de cor lilás, dão um colorido diferente a rua. Ao adentrarmos ao bairro, entre subidas e descidas entre as duas importantes avenidas na parte que podemos classificar como interior do bairro encontramos lombas que transmitem uma sensação maior de inserção ao bairro. 
Percorrendo a Avenida Osvaldo a paisagem vai se modificando progressivamente no que diz respeito aos prédios que no início são construções mais recentes, com prédios mais altos, maior arborização e as próprias árvores são mais fechadas seus arcos de aproximam mais formando uma espécie de corredor de sombra e proteção. No que diz respeito as pessoas o fluxo diminui próximo ao viaduto da Rua Vasco da Gama que em determinada altura direção ao centro mais precisamente onde tem um viaduto transforma-se em Rua Irmão José Otão.

No cruzamento com a Rua Vasco da Gama essa mudança é ainda mais nítida, casas antigas em mau estado de conservação, alguns prédios inacabados. Mas, apesar dessas distinções algo que se verifica de forma constante são as grades seja em prédios como em casas e cercas elétricas.

Neste trecho após viaduto os prédios são menores, em sua maioria de quatro andares e mais antigos, um ao lado do outro, muitos de granitinha ou pastilhas. Quando a rua vai se aproximando da Osvaldo Aranha ela vai se ampliando, e a concentração de estabelecimentos comerciais é maior. Uma venda, pequenas lojas de bijuterias e acessórios, restaurantes e sapateiro. Enquanto a Rua Ramiro Barcellos se amplia em largura, por entre as árvores avista-se a Avenida Osvaldo Aranha. O movimento dado pelo fluxo de pessoas e automóveis, a claridade do sol no período diurno, antes obscurecido pelas árvores e prédios, mas é impactante o concreto, o asfalto da Avenida e o imponente prédio do hospital de Clínicas causa um certo choque para quem até então fazia um trajeto um tanto bucólico, em um ritmo mais calmo, com apenas alguns passantes que andam com um passo mais tranquiilo e uma grande quantidade de funcionários de prédios varrendo ou lavando as calçadas calmamente.

No período que o sol dá lugar as primeiras evidências que está chegando a noite, pessoas circulam com sacolas do hipermercado que fica próximo, ou passeiam com seus cachorros. Na Rua Fernandes Vieira situa-se um Hipermercado, que modifica o fluxo de pessoas, essa rua também é mais ampla e nela está situado o caminho dos parques, uma faixa verde pintada no asfalto que sinaliza que aquele trecho da rua está destinado para a prática da caminhada, da corrida, andar de bicicleta, nos finais de semana e feriados.

Espaço este, que está legitimado e destinado pelo poder público para o lazer e esporte em determinados períodos da semana ou do dia. Esse tipo de espaço criado acaba também por criar um outro tempo social, em que as pessoas modificam suas práticas e organização seu cotidiano em função desse espaço que acaba por modificar o cotidiano dos habitantes da cidade. O que nos faz também refletir sobre a disciplinarização de determinados 
espaços a partir de um organismo como a prefeitura, alterando ou criando novos espaços de práticas cotidianas e rituais no espaço urbano.

$\mathrm{Na}$ Osvaldo Aranha, carros, ônibus, pessoas andando rapidamente, muitas pessoas, placas de pequenos comércios. Esta região na parte do dia é caracterizada pelo intenso comércio e grande número de passantes. Casas antigas e prédios se mesclam, uma loja ao lado da outra, algumas que ainda lembram armarinhos, bancos, ambulâncias do HPS, sinaleira e muitos ruídos. Uma Avenida ampla, com um corredor de ônibus no canteiro central e altas palmeiras, alinhadas por toda a extensão da Avenida. Essas mesmas palmeiras iniciam no HPS e vão alinhadas até a Sarmento Leite.

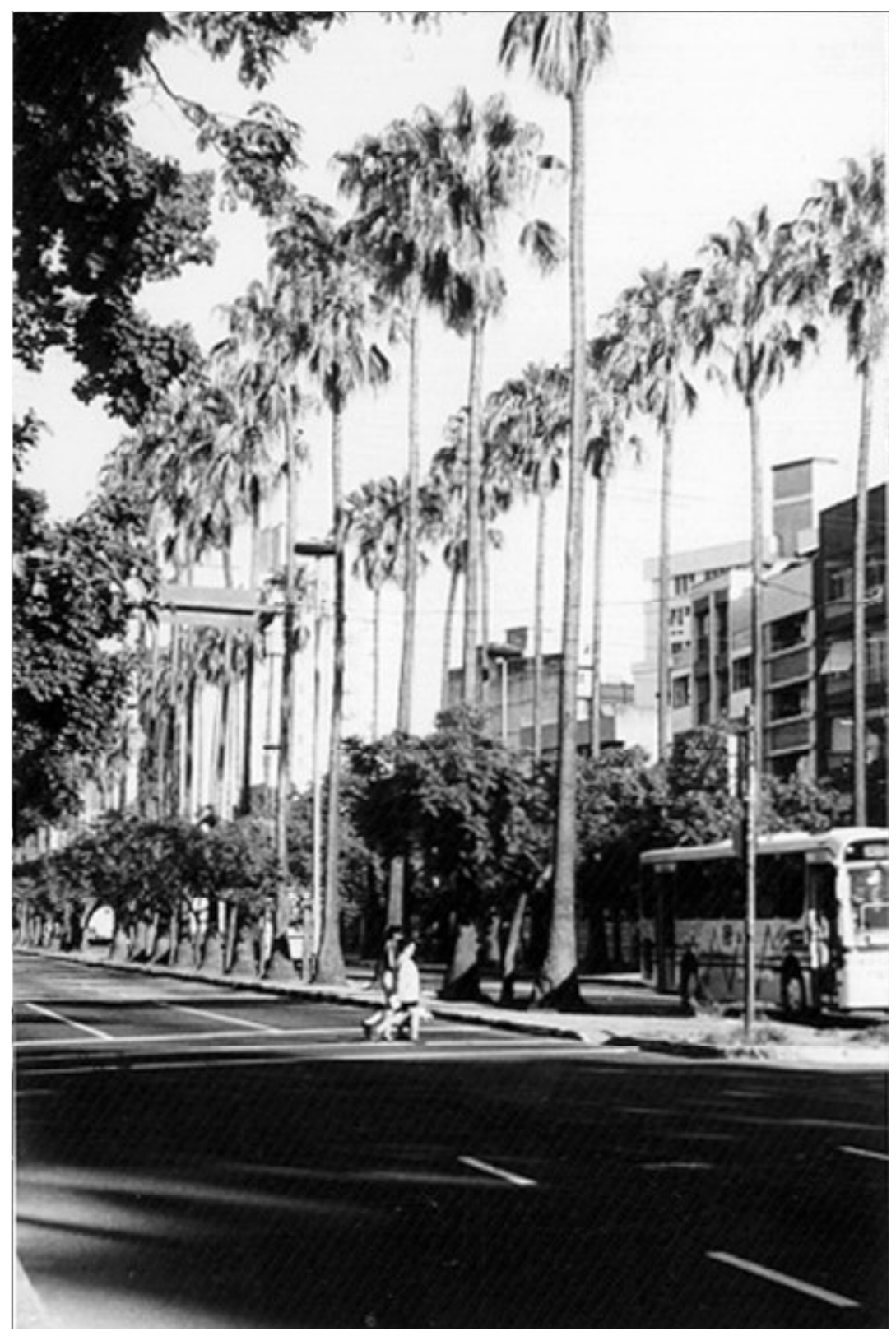




\section{Os Diferentes regimes: Noturno e Diurno}

Como vimos anteriormente, o espaço do bairro vai se modificando no que diz respeito a seu uso e apropriação, seja ele topograficamente, ou em relação à proximidade com outras regiões da cidade.

Na Avenida Osvaldo Aranha encontramos farmácias, lojas de miudezas, bares, restaurantes, bancos. Durante o dia entre os passantes encontramos jovens, idosos, moradores de rua circulando entre as paradas de ônibus lotadas e em meio a calçadas estreitas, dividido espaço com alguns vendedores ambulantes, circulando por entre os murros pichados ou com grafites, forrados de cartazes anunciando shows de bandas, muitos de típicas bandas classificadas de "lado b" da cidade.

Do outro lado da calçada podemos ver o Parque da Redenção, suas árvores, um Parque de diversões, o Mercado Público do BomFim e o auditório Araújo Vianna, onde eventualmente acontecem shows. No período diurno podemos ver muitas pessoas praticando esportes, caminhada e corrida e neste mesmo espaço encontramos jovens sentados nos bancos verdes dispostos na extensão do parque praticando comércio de substâncias ilegais.

Já no período noturno poucos passantes, do lado da calçada, e em alguns lugares, um fluxo grande de pessoas em sua maior parte jovens, reunidos na calçada, e em alguns dias como o Domingo ficam na parte externa dos estabelecimentos como é o caso da Lancheria do Parque e no Mercado Público do BomFim.

No trecho da Av. Osvaldo Aranha, entre as ruas João Telles e Fernandes Vieira está situado um espaço paradigmático da história boêmia do bairro, isto é, a presença da Lancheria do Parque. Na parte térrea de um prédio, entre muitos da Avenida, um letreiro vermelho com letras brancas, anuncia a Lancheria do Parque, que em meio a tantos prédios e estabelecimentos comerciais a profusão de imagens de anúncios e cores a primeira vista, não a destacam. Com portas envidraçadas esse espaço aparentemente pequeno, por ser estreito, surpreende por sua profundidade. Já na entrada do lado esquerdo um balcão que ocupa grande extensão de comprimento, separa o local onde são preparados os lanches e famosos sucos de fruta feitos na hora e servidos na própria jarra do liquidificador em grandes copos de milk shake preparados pelos garçons, os mesmos que circulam por entre as mesas, do espaço onde ficam os habitues e freqüentadores as mesas de mármore branco e madeira, e as paredes onde refletem grandes espelhos. 
Nas distintas temporalidades do dia a Lancheria do parque pode ser um exemplo das diferentes apropriações. Pela manhã a visão e muito diferente da encontrada nesse mesmo local à noite. Poucas mesas ocupadas, a ausência do barulho ensurdecedor da noite. E o público se modifica totalmente, pela manhã nas mesas encontramos praticamente só idosos, há apenas um outro ou outro jovem no balcão.

E no final do balcão os garçons e mais uns senhores conversam, enquanto lêem o jornal. Naquele local estreito, com mesas de mármore, um balcão divide o local da venda de produtos e a preparação dos sucos e lanches, bem como os garçons, que lá ficam, enquanto não circulam por entre as mesas atendendo aos pedidos, ou conversando com os frequientadores. Nas paredes, espelhos, no teto, ventiladores, que mais parecem aros de bicicleta. Senhores que falam baixo, dão risadas, e vão acolhendo os que chegam depois, senhores muitas vezes judeus reunidos na lancheria do parque, falando sobre imóveis, atualidades, transformações.

Do lado da lancheria do Parque alguns prédios, e muitos tapumes, com propagandas de partidos políticos que concorrem a prefeitura de Porto Alegre, grafites, na frente do que era o Cine Baltimore, que agora não existe mais, o processo de demolição foi concluído e resta apenas um vasto terreno cercado pelos tapumes, mas sem nenhum indício de uma nova construção. Ao seu lado, um pequeno prédio fechado, o Bar João, fechado na época da demolição do Cine Baltimore e que ainda não reabriu. Lojas de 1, 99, estacionamento, e na esquina com a Rua João Telles, um sebo, e um prédio antigo, rosa de dois andares, com muitas pichações e grafite, cartazes colados, pichações e cartazes são comumente encontrados e concentrados nessa região. Na parte de baixo, Roseka, uma loja de roupas íntimas, e em cima o Bar Ocidente, outro espaço importante que dá certa identidade para o bairro, no que se refere a boêmia e a noite porto-alegrense, já que é considerado um bar GLS, no qual pela parte da noite promove festas e na parte do dia funciona como um restaurante.

\section{Percorrendo as marcas de distintas temporalidades no bairro BomFim}

No bairro BomFim e na memória de suas transformações a partir dessas caminhadas pelo bairro podemos encontrar alguns fragmentos e instantes de transformações como uma casa antiga, já quase demolida, em que fragmentos da fachada ainda se conservam e neles podemos observar que ainda se mantém a porta da antiga casa e através desta é possível ver um novo prédio surgindo. Estreito, alto, com fachada em granito escuro reluzente. Interessante esta imagem que condensa uma transformação em um pequeno espaço 
do bairro. O nascimento vigoroso de um prédio e a morte lenta de uma casa antiga. Que nos leva a pensar no todo complexo que leva a se chegar a esse nascimento e morte, e a relação deste evento com os demais ocorridos no bairro. Sua descaracterização, o mercado imobiliário e sobre as diferentes formas de estar atento a esses pequenos, mas importantes eventos da vida cotidiana do bairro.

Nesse sentido, trabalhar com um território determinado pertencente a um dos lugares mais significativos para a identidade urbana de Porto Alegre, o bairro BomFim, caracterizado na memória coletiva de seus habitantes pela pluralidade dos seus grupos urbanos evoca a atenção ao que M. De Certeau chama de práticas microbianas, singulares e plurais dos seus habitantes. (De Certeau, 1994)

Michel De Certeau (1994) na obra A Invenção do Cotidiano, convida o leitor a não olhar simplesmente a cidade por uma visão panorâmica, distanciada das práticas comuns de seus habitantes. Segundo o autor, a racionalização urbanística dada pela cegueira em relação aos fluxos e aos movimentos, e a surdez quanto aos ruídos, acaba por produzir entre os seus habitantes um espaço de um não-tempo, criando assim um sujeito universal e anônimo.

Sendo essa visão que se distancia das práticas cotidianas uma marca da modernidade que anseia pelo progresso.

Inicialmente as caminhadas pelo BomFim, seguindo De Certau, foram necessárias para o mapeamento do bairro. Seja pela atenção dada a topografia, as diferentes construções, aos fluxos, bem como pela possibilidade de interação com os atores sociais dos diferentes grupos urbanos.

Imagens que fixei em fotografia e disponibilizadas no acervo do Banco de Imagens e Efeitos Visuais compreende, então, a presença dos vestígios da antiga paisagem do bairro na sua atual fisionomia, somando-se a ela a leitura de notícias e artigos de jornais antigos, de textos de cronistas e de romancistas, os quais foram importantes na busca de elementos que pudessem contar sobre a genealogia, ocupação e as transformações na paisagem e no cotidiano do bairro. 


\title{
Bairro Bom fim: Origem da Ocupação e Transformações
}

\author{
“BomFim: pequeno país - limita-se ao Norte, com as colinas dos Moinhos de \\ Ventos, a Oeste com o centro da cidade; a Leste com a Colônia Africana e mais \\ adiante com Petrópolis e as Três figueiras; ao Sul com a Várzea, do qual é \\ separado pela Avenida Osvaldo Aranha. “ 1
}

A origem da ocupação está relacionada com a grande várzea, atual Parque da Redenção, que ficava fora dos muros da cidade, e era um local que servia de acampamento e de descanso para tropeiros que traziam gado para os matadouros da cidade.

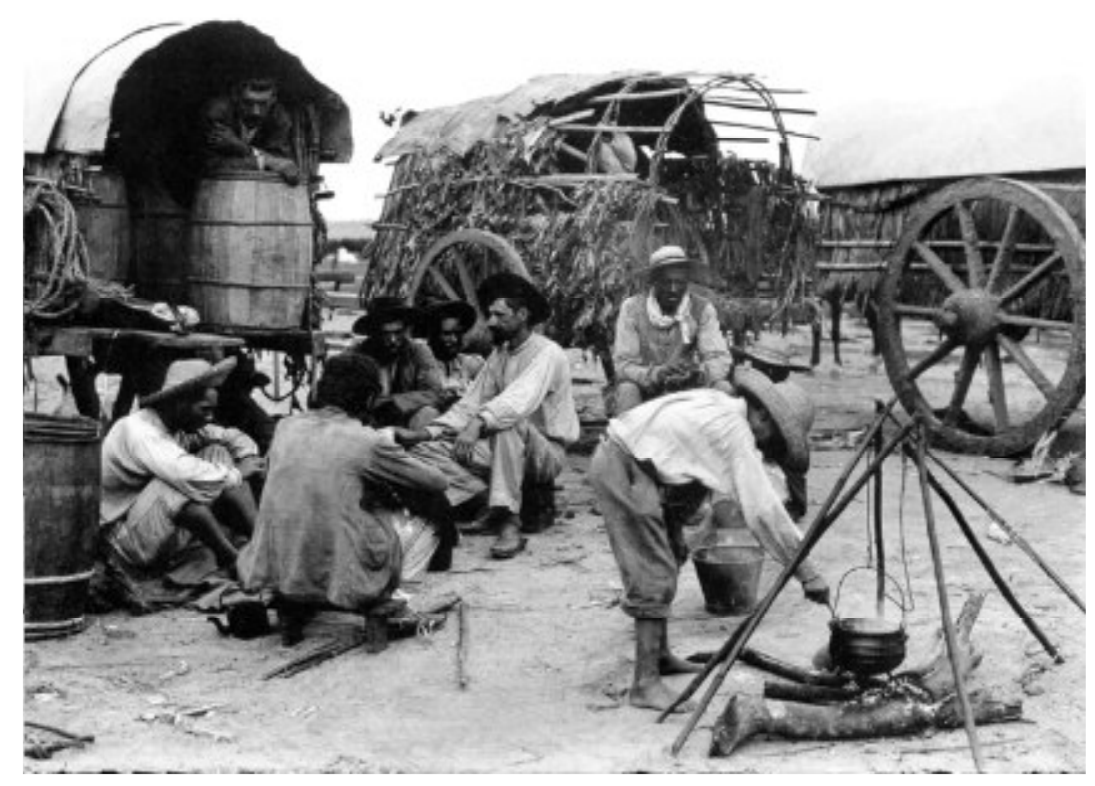

Com a construção da Capela do BomFim em 1867, o campo da Várzea converteu-se em Campo do BomFim. Segundo o cronista Ary Veiga Sanhudo, "era bom mato, com excelente caça, onde inúmeras vezes encontravam seguro abrigo os escravos fugidos". Após a Abolição, muitos libertos, sem ter para onde ir, instalaram-se na região, que passou a chamar-se - extra-oficialmente - de "Campo da Redenção". Esta época também remete a ocupação dos negros e dos seus mocambos e malocas. Onde havia a presença africana no bairro. Pela relação próxima ao local que denominavam colônia africana.

A região também era cortada por uma estrada, o caminho do meio, que ligava o centro da cidade aos arraiais, onde atualmente é a Avenida Osvaldo Aranha, que teve sua abertura no século XIX com o nome de Avenida BomFim.

${ }^{1}$ SCLIAR, Moacir. A Guerra no BomFim. 


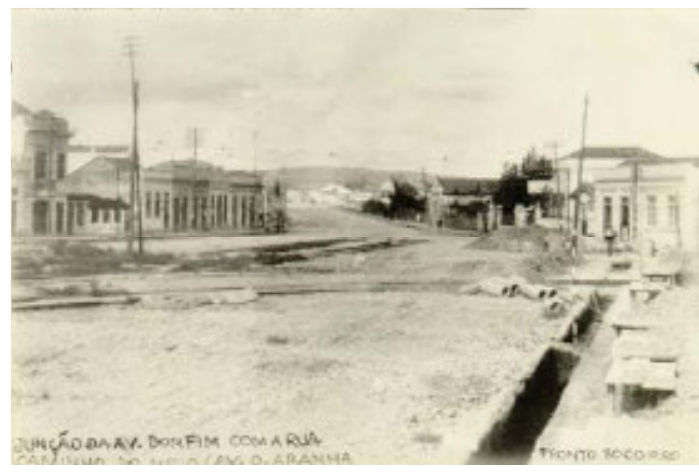

A construção da Escola de Engenharia acabou por trazer mais modificações no espaço do bairro e seu entorno como cita o cronista Achilles Porto Alegre (1921), “com a escola de Engenharia, começou a transformação de um imenso trecho da várzea. Vieram os grandes, mas pesados edifícios das escolas de Direito e Medicina, e depois por ali afora, do lado da escola militar foram surgindo quadras de casas particulares, pois a intendência (...) vendeu-os por um preço cômodo, a diversos pretendentes em 1911..." .

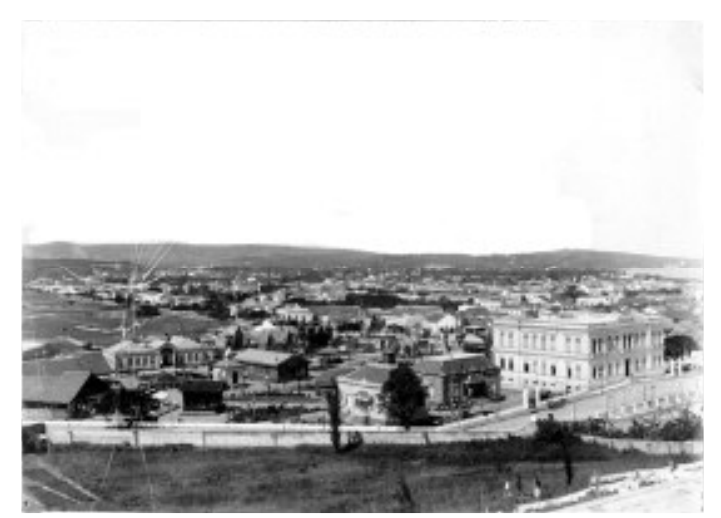
Portanto, o território do bairro BomFim foi importante ponto de sociabilidade desde seus primórdios, em 1901, com a criação oficial do Parque Farroupilha, na época Parque da Redenção, que já servia como importante local de encontro e de sociabilidade coletiva para os habitantes locais e de outros arrabaldes.

Segundo o relato historiográfico, foi a partir da Exposição Internacional nos antigos Campos da Várzea, em 1901, que esta área que faz divisa com o bairro BomFim foi valorizada e as autoridades passaram a preocupar-se com o arruamento, a higienização e a iluminação do lugar". Além destes relatos, o surgimento do bairro BomFim na paisagem urbana portoalegrense esta marcado pela imigração judaica para esta região da cidade, ao longo de todo o século XX.

Em 1935, ocorreria uma segunda exposição internacional na área do Parque, que passou a ser denominado, desde aí, em Parque Farroupilha. Segundo relata uma reportagem do Diário de Notícias, precisamente do 21 de setembro de 1935, data da inauguração da referida exposição: "O movimento da cidade, desde as primeiras horas da manha foi extraordinário. De todos os quadrantes da capital dirigiram-se para o Parque Farroupilha, atual nome do campo da Redenção, milhares de pessoas. Os bondes trafegavam repletos de passageiros. Automóveis às centenas, cortavam as ruas em todos os sentidos“".

Em sua feição atual, a paisagem urbana do BomFim ainda condensa focos de sobrevivência do tempo, através de casas antigas, por entre prédios, mas o que se verifica são espaços que privilegiam o encontro, caracterizando-o um bairro onde encontramos espaços de 
importantes de sociabilidade publica: bares, restaurantes, cafés e lancherias, igrejas e sinagogas, centros culturais e esportivos, etc.

Segundo A. L. C. Rocha (2001), o gosto pela aglomeração faz do BomFim um bairro tradicional da cidade de Porto Alegre, evocando em sua sociabilidade polimórfica, uma mistura tensional de espaços morais e éticos distintos. Segundo a autora, "não por acaso, o BomFim é sempre, e eternamente, atingido pela preocupação com os efeitos morais malignos do caos e da desordem do espaço urbano. Território assolado por processos de desfiguração de seu patrimônio edificado, o BomFim não é apenas lugar de enraizamento da aventura e da boêmia, mas do policial, região da cidade atingida por ondas de ações discursivas que tentam associá-lo a violência, a delinquiência e a criminalidade urbana local.”

Se pode observar as transformações na paisagem do bairro BomFim e nas formas de ocupação deste território, devido a sobreposição das camadas temporais acaba por criar um depósito de sociabilidades, nas quais podemos buscar uma apreensão da adesão afetiva e dos significados destes espaços, para os diferentes grupos que convivem neste território da cidade.

Tendo em vista as transformações neste espaço-tempo, os moradores modificam as práticas e as formas de se relacionar com o espaço. Criando assim, diferentes formas sociabilidade e de itinerários no espaço da rua, também seguindo as distintas temporalidades, a do dia e a da noite.

Os diferentes processos incluindo o de modernização do bairro alteraram a sua feição de bairro residencial familiar para um bairro habitado por estudantes ou casais jovens. Sendo que muitos destas famílias que habitavam o bairro anteriormente se deslocaram para outros espaços da cidade, principalmente para bairros de classe alta, como o Bela Vista e o Moinhos de Vento, bairros mais jovens que assumiram a feição de bairros com hábitos, práticas e representação de espaços de prestígio (SALVATORI, 1996).

As novas gerações de judeus e outras famílias abriram espaço para a vinda de estudantes universitários, pela proximidade com a Universidade Federal e casais jovens, bem como, de migrantes do interior do estado onde muitos destes assumiram pequenos estabelecimentos comerciais, ou bares e restaurantes. Além disso, acabaram por se apropriar do bairro, trazendo outros parentes e pessoas de sua relação, criando espaços pautados por redes de parentesco e sociabilidade, tornando o espaço da cidade grande, da capital um espaço mais familiar em seu duplo sentido.

Este é o caso de Éversson, 38 anos, informante que conheci durante as caminhadas, dono de uma fruteira situada na Rua Fernandes Vieira, vindo do interior do 
estado, da cidade de Encantado, relata sua experiência em outro bairro da cidade e sua relação com o BomFim:

\footnotetext{
"Já morei na Azenha, mas era diferente daqui, aqui é um bairro família, as pessoas se encontram na rua, pra tomar chimarrão na Redenção, tenho muitos amigos que vieram do interior também que moram aqui perto, me sinto em casa aqui, na Azenha parece que as pessoas não são abertas como aqui."
}

A fala de Éversom pode nos remeter ao que MAGNANI (1984: 137) caracteriza de "Pedaço", para o autor são 2 elementos básicos ao pedaço: um componente de ordem espacial a que corresponde a uma determinada rede de relações sociais.

Falou-me então de sua trajetória, que havia vindo do interior para trabalhar na capital, inicialmente morou e trabalhou na Azenha. Contou-me que era natural da cidade gaúcha do interior do Estado, Encantado, mais uma vez me surpreendi, pois, em outras situações em que estava no BomFim, e até na cidade baixa, bairro vizinho e também boêmio, quando percebia o sotaque característico e os traços de descendentes de italianos dos garçons dos bares ou restaurantes com quem tive contato, falava alguma palavra do dialeto italiano e em seguida perguntava qual era a sua cidade de origem, me responderam em quatro casos que eram da cidade de encantado.

Éversson relatou que na Avenida Osvaldo Aranha, um dos estabelecimentos mais tradicionais, a Lancheria do Parque, também é dirigido por pessoas vindas da mesma região. E que há muitos amigos dele, que também vieram da sua cidade que se estabeleceram no bairro, a venda ele havia comprado de um conhecido de sua cidade de origem.

Já outra informante privilegia em sua narrativa o espaço do bairro e suas motivações para a escolha do BomFim, como bairro para morar e trabalhar, através dos pontos que considera positivo no local. Mafalda, 60 anos, natural de Erechim, que veio para Porto Alegre para trabalhar como empregada doméstica muda-se com a família de judeus para a Avenida Osvaldo Aranha há 30 anos atualmente moradora de um conjunto habitacional composto de moradores de baixa renda, em uma das ruelas do BomFim, relata:

\footnotetext{
"Antes a gente ia para a "Redenção" e ficava até às 10 da noite, a gente ia para namorar, eu levava a minha filha pequena e dizia para ela me chamar de tia, aí ela me chamava: titiamamãe, eu só ria e procurava disfarçar. Os rapazes pagavam pipoca e doces, tinham também bailes de noite na Redenção e no Araújo Vianna. Ih menina! Hoje não dá pra ir quando escurece... nem passo perto.."
} 


\section{Pluralidade de tradições}

O Bairro BomFim pode representar o que Gilberto Velho (1999) caracteriza de pluralidade de tradições como característica essencial de nossa sociedade, enquanto sociedade complexa onde há profunda divisão social do trabalho e a presença de uma heterogeneidade cultural. As diferentes tradições coexistem também se verificando problemas de comunicação entre os diversos grupos delas portadoras e a partir disso, também se podem distinguir certos paradigmas culturais mais significativos e com maior potencial de difusão que outros. Assim, verificando-se uma permanente contradição entre as particularizações de experiências que se expressam culturalmente através de símbolos homogeneizadores. (VELHO, 1999).

O Bairro BomFim na sua pluralidade tem sua identidade representada muitas vezes a território de judeus pela localização da colônia judaica da cidade, a bairro universitário pela proximidade com a Universidade, e sua imagem é muitas vezes associada a um território violento, habitado por gangues e galeras oriundas de outros bairros da cidade para este local, até como área residencial, como um bairro histórico para o patrimônio cultural da cidade.

\section{Segundo Eunice Durham}

\footnotetext{
"o grupo que reelabora e utiliza o produto cultural tende a ser diferente daquele que o produziu. Estando a distinção entre produtores e consumidores de cultura presa a uma distinção de classe, a relação entre eles assume necessariamente uma conotação política, isto é, ela tem implicações em termos de poder." Assim, as diferenças culturais aparecem, não como simples expressão de particularidades do modo de vida, mas como manifestação de oposições ou aceitações que implicam num constante reposicionamento dos grupos sociais na dinâmica das relações de classe." (Durham, 1997, p. )
}

Os espaços públicos do bairro BomFim como a Avenida Osvaldo Aranha seu comércio, bares, bem como o Parque da Redenção pode ser considerado como importante foco de sociabilidades, pelos encontros nesse espaço urbano.

Espaço este configurado e reconfigurado pelos grupos urbanos que dele se apropriam. Seja para consumo, passeio, apenas pelo trajeto, com a distinção dada pelas diferentes temporalidades do dia ou da noite um exemplo disso é a lancheria do Parque localizada na Avenida Osvaldo Aranha em que pela manhã encontramos senhores idosos tomando café da manhã ou almoçando, conversando; enquanto a noite podemos encontrar um 
maior número de jovens ocupando esse mesmo espaço. Mesmo que as idades variem de acordo com a temporalidade, o que se percebe é a busca do encontro com o outro.

Assim, a temporalidade cotidiana é percebida na forma de vivenciar, por uma espécie de lógica afetiva, que está relacionada com as redes de relações destes indivíduos.

A temporalidade também pode ser dada pela outra contagem do tempo, no sentido do tempo de residir, pelas lembranças, da memória coletiva (Halbwachs, 1990) vista de dentro dos grupos ou pela história, ou seja, a visão de fora pelo círculo e pelo cultivo das tradições desse próprio grupo.

\section{Considerações finais}

A pesquisa de campo tem levado a ampliação das perspectivas de tempo para o registro da ocupação e dos decorrentes significados atribuídos aos diferentes territórios do bairro, surgindo a necessidade de mais relatos de habitantes e frequientadores. Alguns relatos apontam à importância de espaços públicos e privados pela por serem espaços de sociabilidade relacionados ao seu estilo de vida, e o modo que vivenciam quotidianamente o bairro e a cidade. Verifica-se a valorização de locais que Hilmann (1993), caracteriza de lugares de encontro, de pausa na cidade, para o corpo, onde se torne possível a intimidade. Assim, retomando o que foi o objetivo da construção das cidades, o querer estar junto, imaginar, falar, fazer e tocar e segundo ele as esquinas, cantos, enfim pausas para se estar junto como cafés, lanchonetes, parques são importantes pontos para que ocorra este estar junto na cidade.

\section{REFERÊNCIAS:}

DE CERTAU, Michel. A Invenção do Cotidiano: 1. Artes de Fazer. Petrópolis/RJ: Vozes. 1994 DURHAM, Eunice Ribeiro. A Dinâmica cultural na sociedade moderna. Ensaios de opinião. (2-2) : 1997.

ECKERT, Cornelia e ROCHA, Ana Luiza Carvalho da. "Etnografia de Rua: Estudo de Antropologia Urbana". In: RUA, Revista do Núcleo de Desenvolvimento da Criatividade da Unicamp - NUDECRI - Campinas, março 2003, número 9. p. 101 a 127. 
GEERTZ, Clifford. A interpretação das culturas. Rio de Janeiro, Zahar, 1978. (2 ed.). HILMANN, James. Cidade \& Alma. Studio Nobel, São Paulo, 1993.

MAGNANI, José Guilherme Cantor. Festa no Pedaço, Cultura Popular e Lazer na Cidade. Ed. Brasiliense. São paulo. 1984

ROCHA, Ana Luiza Carvalho da. Bom fim: Feições de uma cidade no Plural ....ou o lugar da Desordem. In: Iluminuras. Número 30. Porto Alegre Banco de Imagens e Efeitos Visuais, PPGAS/UFRGS, 2001.

SALVATORI, Elena. Nem tudo que Reluz é ouro: Estilo de Vida e Sociabilidade na Construção de um Espaço Urbano de Prestígio em Porto Alegre/RS,. Dissertação de mestrado em antropologia Social, PPGAS/IFCH/UFRGS, 1996.

VELHO, Gilberto. Individualismo e Cultura - Notas para uma Antropologia da Sociedade Contemporânea. Jorge Zahar Editor Ltda. Rio de Janeiro, 1997.

\section{ÍNDICE DE IMAGENS E ILUSTRAÇÕES:}

\section{Página 06}

Fotografia da pesquisadora. Acervo BIEV.

Demolição do Cine Baltimore, Av. Osvaldo Aranha. 2004.

Página 07

Acima: Fotografia da pesquisadora. Acervo BIEV. Av.

Osvaldo Aranha. 2004.

Abaixo: Patrícia Rodolpho. Acervo BIEV. Av.

Osvaldo Aranha. 2002.

Página 08

Sandra Tartas da Rosa. Acervo BIEV. Parque da

Redenção. 2002.

\section{Página 9}

Arquivo digital PROCEMPA.

Detalhe mapa de Porto Alegre. Acessado em 2005.

\section{Página 11}

Fotografia da pesquisadora. Acervo BIEV. Av.

Osvaldo Aranha, 2004.

Página 15

Lunara. Acervo BIEV. Campo da

Redenção. 1903.

Página 16

Acima: Autor desconhecido. Acervo BIEV. Av.

Osvaldo Aranha. Início século XX.

Abaixo: W. Hoffmann Harnisch Filho. Acervo BIEV.

Vista Bom fim. Início século XX. 